\title{
Quantitative Determination of Bromine and Iodine in Food Samples Using ICP-MS
}

\author{
Thi Kim Dzung NGuYeN*广 and Rainer LudwiG** \\ *Center for Analytical Chemistry, Institute for Technology of Radioactive and Rare Elements, 48 Lang-Ha, \\ Hanoi, Vietnam \\ **Institute of Chemistry, Freie Universität Berlin, Fabeckstr. 34-36, 14195 Berlin, Germany
}

\begin{abstract}
Trace concentrations of bromine and iodine in food samples and certified reference materials (CRMs) were determined by an inductively coupled plasma-mass spectrometry (ICP-MS) technique after low-power microwave digestion and extraction into an aqueous quaternary ammonium hydroxide solution. The recovery after sample preparation was quantitative. The internal standard for the measurement of the analyte on ICP-MS was optimized in this study. The detection limits were 0.19 and $0.68 \mathrm{ng} \mathrm{g}^{-1}$ for I and $\mathrm{Br}$, respectively, when a $10 \mathrm{ng} \mathrm{g}^{-1} \mathrm{Te}$ solution as an internal standard was used, applying the signal of ${ }^{125} \mathrm{Te}$. The high recovery and reproducibility are sufficient for the quantitative analysis of these elements, and the analytical procedure is recommended for the analysis of $\mathrm{Br}$ and $\mathrm{I}$ in various kinds of bio-samples.
\end{abstract}

Keywords Bromine, iodine, food samples, ICP-MS

(Received August 8, 2014; Accepted September 30, 2014; Published November 10, 2014)

\section{Introduction}

The presence of bromine compounds in food, e.g. that of organic bromines needs to be controlled due to its toxicity. ${ }^{1}$ It originates for example from pesticides and fumigants, ${ }^{2}$ and food additives such as brominated vegetable oil. ${ }^{3}$ The occurrence of bromide as a residue in food and water necessitated its broad toxicological evaluation. ${ }^{4}$ On the other hand, iodine is an essential element for the human body, and is therefore used in nutrition; insufficient levels of iodine in food can cause deficiency problems. ${ }^{1,5}$

The determination of $\mathrm{Br}$ and $\mathrm{I}$ in biological samples is hampered due to their trace concentrations $\left(\mu \mathrm{g}^{-1}\right.$ or lower), the risk of loss during sample preparation, the volatility of the molecular forms, and the excess of chloride in the matrix..$^{6,7} \mathrm{~A}$ review on the speciation of iodine compounds in environmental and bio-samples shows that the choice of the analytical method depends on the type of compound and the matrix. ${ }^{8}$ Organic $\mathrm{Br}$ and I compounds in bio-samples have routinely been identified by chemical techniques following their isolation, and by modem spectroscopic methods, such as by GC,, 910 HPLC and HPLC hyphened inductively coupled plasma-mass spectrometry (ICP-MS) ${ }^{8}$ Total halogen $(\mathrm{Br}, \mathrm{I})$ in food was analyzed by ICP-OES and ICP-MS,,$^{11,12}$ and other methods.

The purpose of this study was to set up a method for total $\mathrm{Br}$ and I analysis in bio-samples with acceptable uncertainties at levels relevant to food control, and its validation. ICP-MS is nowadays common for trace-element analysis. However, the quantitative determination of total $\mathrm{Br}$ and I faces difficulties, such as volatility and a memory effect, the molecular iodine

$\dagger$ To whom correspondence should be addressed.

E-mail: ntkdung@vinatom.gov.vn formed in acidic media is adsorbed to the tubing and glass surface during sample introduction, making a rapid return to background levels very slow.,13,14 The matrix of biological samples also caused interference with ICP-MS measurements of these elements, and increased uncertainties of the analytical results. Therefore, an internal standard is applied in these measurements. Determining the most suitable internal standard was another goal of this work.

\section{Experimental}

Reagents and chemicals

All chemicals were of analytical grade. The experiments were performed at $\mathrm{T}=298 \mathrm{~K}$. Deionized, distilled water $\left(18 \mathrm{M} \Omega \mathrm{cm}^{-1}\right)$ was used for preparing the aqueous solutions. Commercially available standard solutions $\left(\mathrm{Br}^{-}\right.$and $\mathrm{I}^{-}$of chromatographic grade, Dionex) were used for calibration in ICP-MS. Stock solutions of Te, Rh, Re, Ge and Eu as internal standards (IS) were prepared by diluting commercially available standard solutions or by dissolving adequate amounts of their pure nitrate salts in distilled water. Mixed and single element internal standard solutions were prepared from these stock solutions.

\section{Apparatus}

The Agilent (USA) Model 7500a ICP-MS, controlled by Chemstation software, was used for the measurements. The optimized instrumental operating conditions are as follows: RF power, $1410 \mathrm{~W}$; RF matching, $1.45 \mathrm{~V}$; sample uptake time, $60 \mathrm{~s}$; sample uptake rate, $0.4 \mathrm{rps}$; sample depth, $6.2 \mathrm{~mm}$; Ar coolant flow rate, $15 \mathrm{~L} \mathrm{~min}^{-1}$; carrier gas, $1.2 \mathrm{~L} \mathrm{~min}^{-1}$; auxiliary gas, $0.9 \mathrm{~L} \mathrm{~min}^{-1}$; water RF/TP flow rate, $2.4 \mathrm{~L} \mathrm{~min}^{-1}$; water RF/TP, $\mathrm{T}=293 \mathrm{~K}$; analyzer pressure, $3 \times 10^{-4}$ to $2 \times 10^{-3} \mathrm{~Pa}$. Between 
two measurements it was rinsed with a $0.1 \%$ ammonia solution and $\mathrm{H}_{2} \mathrm{O}$.

The microwave sample digestion system (Q45 ENVIROPREP), which is equipped with microwave power from 0 to $100 \%$ $(1000 \mathrm{~W})$, was used for the treatment of bio-samples. The vessels $(\mathrm{V}=50 \mathrm{~mL})$, made of PTFE, are designed to release at $220 \mathrm{psi}$ and $473 \mathrm{~K}$.

\section{Sample preparation}

The food samples used for this study were: young leaves of cabbage (Brassica oleracea capitata), water spinach (Ipomoea aquatica), and water coriander (Limnophila aromatica). After collecting from the field they were well cleaned with distilled $\mathrm{H}_{2} \mathrm{O}$, dried in a vacuum and ground to a powder. A weighed sub-sample $(0.10$ to $0.20 \mathrm{~g})$ was transferred into a $50 \mathrm{~mL}$ PTFE vessel and moistened with distilled $\mathrm{H}_{2} \mathrm{O}$. Tetramethylammonium hydroxide $(0.5 \mathrm{~mL}$ of $25 \%$ aqueous solution) and $4.5 \mathrm{~mL}$ distilled $\mathrm{H}_{2} \mathrm{O}$ were added. A total of 12 samples were placed on a rotary table. The program for the microwave oven is listed in Table 1. The parameters of the sample treatment allow complete dissolution and quantitative recovery, as checked with certified reference materials (CRMs) (Table 3). After digestion, the sample solutions were neutralized with $\mathrm{HNO}_{3}$, filtered through a $0.45 \mu \mathrm{m}$ membrane into volumetric flasks and diluted with $\mathrm{H}_{2} \mathrm{O}$.

\section{Results and Discussion}

Selection of isotopes for quantitative analysis and detection limits

The isotopes for quantitative analysis are selected by the typical characters, such as the absence of spectral overlapping, high isotopic abundance and more ion counts within an integration time. ${ }^{79} \mathrm{Br}$ and ${ }^{81} \mathrm{Br}$ are stable isotopes of $\mathrm{Br}$, and are usually selected as the index atomic mass, while iodine has only ${ }^{127} \mathrm{I}$ as stable isotope with $100 \%$ abundance.

$\mathrm{Br}$ and $\mathrm{I}$ are nonmetallic elements, and are rather difficult to

Table 1 Operating conditions of the microwave system

\begin{tabular}{ccc}
\hline Step & Power/W & Time/min \\
\hline 1 & 300 & 5 \\
2 & 600 & 3 \\
3 & 300 & 5 \\
\hline
\end{tabular}

analyze by using ICP-MS, especially at low levels and in the presence of excess of matrix elements (see Introduction section). ${ }^{13}$ This may cause a low reproducibility of the measurement results and large uncertainties. In order to overcome this problem, the internal standards were selected from several elements cited in references, such as $\mathrm{Cs}, \mathrm{Ge}, \mathrm{Sb}$, $\mathrm{Bi}, \mathrm{Ce}, \mathrm{Pr}, \mathrm{Eu}, \mathrm{Te}, \mathrm{Tl}, \mathrm{In}, \mathrm{Rh}$, and Re. ${ }^{11,13,15-20}$ According to the general principles for choosing an internal standard to measure $\mathrm{Br}$ and $\mathrm{I}$, elements that are rarely contained in the studied food samples, having similar ionization potentials as $\mathrm{Br}$ and $\mathrm{I}$, and providing relatively stable signals with high sensitivity were tested. The measured isotopes were ${ }^{72} \mathrm{Ge},{ }^{103} \mathrm{Rh},{ }^{125} \mathrm{Te},{ }^{128} \mathrm{Te}$, ${ }^{130} \mathrm{Te},{ }^{151} \mathrm{Eu},{ }^{153} \mathrm{Eu},{ }^{185} \mathrm{Re}$, and ${ }^{187} \mathrm{Re}$. These internal standards were prepared in a mixed solution at $10 \mathrm{ng} \mathrm{g}^{-1}$ concentration of each element together with a certain amount of iodide and bromide. The measurement was then carried out under identical conditions (see Experimental section).

The limits of detection (LOD) were calculated as the $3 \sigma$ standard deviation of at least seven determinations of a blank solution; ${ }^{21}$ the results are given in Table 2 . The sensitivity of each element was denoted as the average value of the ratio between its intensity (count per second, cps) and the intensity of the element being used as an internal standard (IS) being measured in a blank solution with that of a solution containing $3 \mathrm{ng} \mathrm{g}^{-1}$ of each studied element.

It can be seen from Table 2 that the LOD of $\mathrm{Br}$ and $\mathrm{I}$ in ICP-MS when using five elements as internal standards gave better LOD values than that of direct measurements, except for the use of ${ }^{151} \mathrm{Eu}$. LODs of both studied halogens when introducing ${ }^{72} \mathrm{Ge}$ and ${ }^{125} \mathrm{Te}$ were the best, and lower than in references. ${ }^{11,20}$ The sensitivity of $\mathrm{Br}$ and I derived from the intensities (count per second) measured in blank solutions and in solutions containing $3 \mathrm{ng} \mathrm{g}^{-1}$ (ppb) of each element by ICP-MS was sufficient for quantification at the desired concentration levels.

\section{Linearity and standard calibration}

The wide range of linearity is one advantage of ICP-MS, which can be valid from the blank value up to hundreds of $\mu \mathrm{g} \mathrm{g}^{-1}$ of each studied element. Due to the relatively low concentration of the investigated elements in the studied sample, however, the calibration standards were measured in the range from $2 \mathrm{ng} \mathrm{g}^{-1}$ up to $200 \mathrm{ng} \mathrm{g}^{-1}$. The standard calibration curves for $\mathrm{Br}$ and I were established from the measurement of a set of various $\mathrm{Br}$ and $\mathrm{I}$ concentrations in the respective presence of

Table 2 Limit of detection and sensitivity

\begin{tabular}{|c|c|c|c|c|c|c|c|}
\hline $\begin{array}{c}{ }^{79} \mathrm{Br} \text { with internal } \\
\text { standard }\end{array}$ & $\mathrm{LOD}^{\mathrm{a} / \mathrm{ng} \mathrm{g}^{-1}}$ & $\begin{array}{c}\text { Ratio }\left({ }^{79} \mathrm{Br} \mathrm{cps} / \mathrm{IS}\right. \\
\mathrm{cps}) \text { at blank }\end{array}$ & $\begin{array}{l}\text { Ratio }\left({ }^{79} \mathrm{Br} \mathrm{cps} / \mathrm{IS}\right. \\
\mathrm{cps}) \text { at } 3 \mathrm{ng} \mathrm{g}^{-1}\end{array}$ & $\begin{array}{l}{ }^{127} \mathrm{I} \text { with internal } \\
\text { standard }\end{array}$ & $\mathrm{LOD} / \mathrm{ng} \mathrm{g}^{-1}$ & $\begin{array}{l}\text { Ratio }\left({ }^{127} \mathrm{I} \mathrm{cps} / \mathrm{IS}\right. \\
\text { cps) at blank }\end{array}$ & $\begin{array}{l}\text { Ratio }{ }^{127} \mathrm{I} \mathrm{cps} / \mathrm{IS} \\
\text { cps) at } 3 \mathrm{ng} \mathrm{g}^{-1}\end{array}$ \\
\hline${ }^{72} \mathrm{Ge}$ & $0.44(0.73)$ & 0.039 & 0.060 & ${ }^{72} \mathrm{Ge}$ & 0.17 & 0.157 & 0.338 \\
\hline${ }^{103} \mathrm{Rh}$ & $0.85(1.40)$ & 0.009 & 0.013 & ${ }^{103} \mathrm{Rh}$ & 0.24 & 0.035 & 0.074 \\
\hline${ }^{125} \mathrm{Te}$ & $0.68(0.90)$ & 0.131 & 0.206 & ${ }^{125} \mathrm{Te}$ & 0.19 & 0.525 & 1.157 \\
\hline${ }^{128} \mathrm{Te}$ & $0.75(1.05)$ & 0.027 & 0.043 & ${ }^{128} \mathrm{Te}$ & 0.21 & 0.110 & 0.240 \\
\hline${ }^{130} \mathrm{Te}$ & 0.77 (1.13) & 0.024 & 0.038 & ${ }^{130} \mathrm{Te}$ & 0.21 & 0.098 & 0.212 \\
\hline${ }^{151} \mathrm{Eu}$ & $2.28(4.75)$ & 0.004 & 0.005 & ${ }^{151} \mathrm{Eu}$ & 0.55 & 0.015 & 0.030 \\
\hline${ }^{153} \mathrm{Eu}$ & $1.21(2.20)$ & 0.003 & 0.005 & ${ }^{153} \mathrm{Eu}$ & 0.29 & 0.013 & 0.027 \\
\hline${ }^{185} \mathrm{Re}$ & $1.11(1.91)$ & 0.006 & 0.009 & ${ }^{185} \mathrm{Re}$ & 0.29 & 0.026 & 0.053 \\
\hline${ }^{187} \mathrm{Re}$ & $1.13(1.95)$ & 0.003 & 0.004 & ${ }^{187} \mathrm{Re}$ & 0.29 & 0.012 & 0.024 \\
\hline \multirow{2}{*}{$\begin{array}{l}\text { Measuring }{ }^{79} \mathrm{Br} \\
\text { directly }\end{array}$} & \multirow{2}{*}{$1.53(3.20)$} & cps of blank & cps of $3 \mathrm{ng} \mathrm{g}^{-1}$ & \multirow{2}{*}{$\begin{array}{l}\text { Measuring }{ }^{127} \mathrm{I} \\
\text { directly }\end{array}$} & \multirow{2}{*}{0.34} & cps of blank & cps of $3 \mathrm{ng} \mathrm{g}^{-1}$ \\
\hline & & 1464.55 & 2308.52 & & & 6631.43 & 12960.69 \\
\hline
\end{tabular}

a. The value in parenthes is denoted the LOD of ${ }^{81} \mathrm{Br}$ at each internal standard used. 

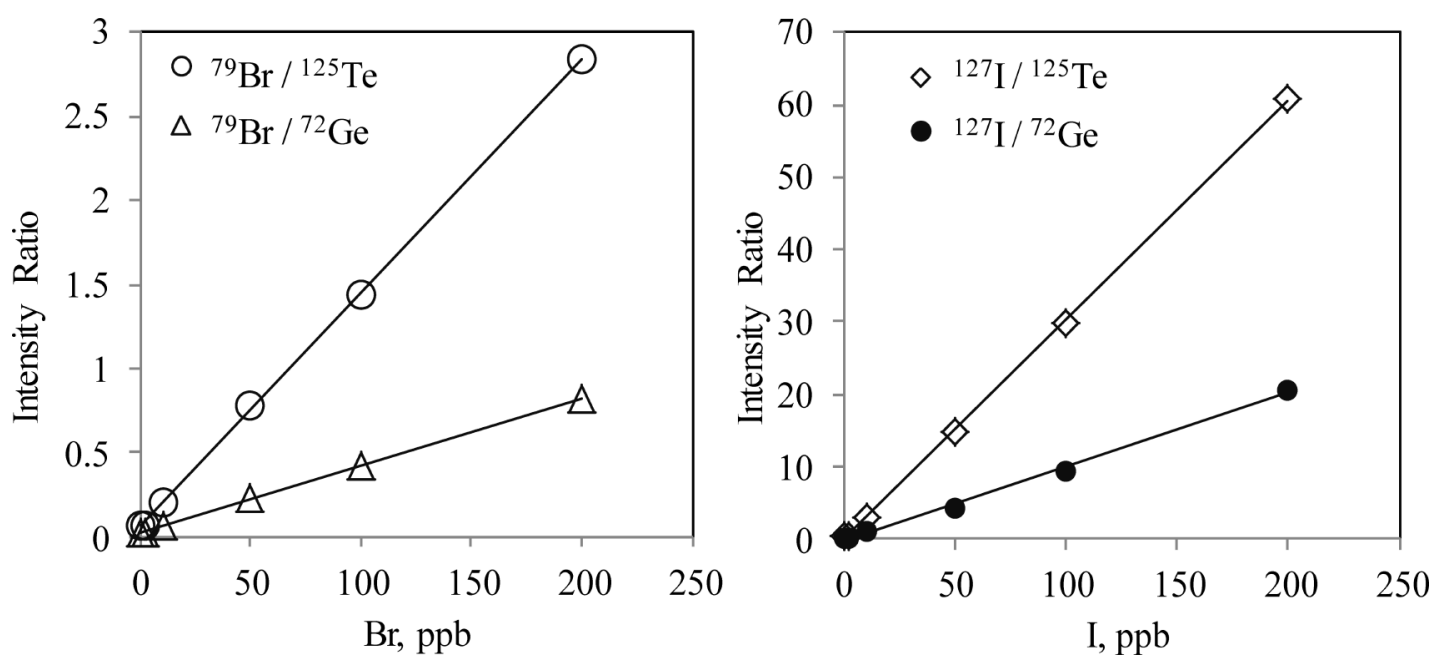

Fig. $1 \mathrm{Br}$ and I external calibration curves using ${ }^{72} \mathrm{Ge}$ and ${ }^{125} \mathrm{Te}$ as internal standards. Uncertainties from replicate measurements were $<1 \%$.

Table 3 Recovery of bromine and iodine using internal standards

\begin{tabular}{ccccc}
\hline \multirow{2}{*}{$\begin{array}{c}\text { Studied } \\
\text { element }\end{array}$} & Internal & Correlation & \multicolumn{2}{c}{ Recovery, \% } \\
\cline { 4 - 5 } & standard & factor $r^{2}$ & $\begin{array}{c}\text { Using internal } \\
\text { standard }\end{array}$ & $\begin{array}{c}\text { Conventional } \\
\text { calibration }\end{array}$ \\
\hline \multirow{2}{*}{$\mathrm{Br}$} & ${ }^{72} \mathrm{Ge}$ & 0.9989 & 97.66 & 87.23 \\
& ${ }^{125} \mathrm{Te}$ & 0.9998 & 99.32 & \\
$\mathrm{I}$ & ${ }^{72} \mathrm{Ge}$ & 0.996 & 97.65 & 88.46 \\
\hline
\end{tabular}

$10 \mathrm{ng} \mathrm{g}^{-1}$ each of $\mathrm{Ge}, \mathrm{Rh}, \mathrm{Te}, \mathrm{Eu}$ and Re. Figure 1 shows calibration curves for $\mathrm{Br}$ and I using ${ }^{72} \mathrm{Ge}$ and ${ }^{125} \mathrm{Te}$ as internal standards as examples.

As can be seen from Fig. 1, the external calibration curves established for both $\mathrm{Br}$ and I using ${ }^{125} \mathrm{Te}$ show a better linearity with higher correlation factors (Table 3 ) compared with ${ }^{72} \mathrm{Ge}$, and would thus be employed for the determination of these elements in studied samples.

For determining the recovery of $\mathrm{Br}$ and I, a CRM was used (CRM IAEA-153; milk powder matrix; $\mathrm{Br}$ is certified; $\mathrm{I}$ is an information value). From the experimental results (Table 3), a higher recovery of both $\mathrm{Br}$ and I concentrations was obtained when ${ }^{125} \mathrm{Te}$ was introduced as the internal standard, in comparison with the results from the conventional external calibration. Meanwhile the recovery of these elements with the use of ${ }^{72} \mathrm{Ge}$ as an internal standard gave a slightly lower value.

These above-mentioned results demonstrate that $\mathrm{Br}$ and I can be accurately recovered with the support of internal standards, which indicates that there are no common interferences present in the sample. The effective usage of $1 \mu \mathrm{g} \mathrm{g}^{-1}{ }^{125} \mathrm{Te}$ as an internal standard for the determination of iodine (and bromine) in chicken egg samples was also confirmed by Austrian researchers. ${ }^{22}$

\section{Analysis of the certified reference material}

Two CRMs (CRM IAEA-140/TM with a matrix of seaweed powder, and CRM IAEA-153, see above) were used for validation of the method. These CRMs were analyzed using the same procedure described above with 7 replicates; the results
Table 4 Analysis of the certified reference materials

\begin{tabular}{|c|c|c|c|c|c|}
\hline CRM & Element & $\begin{array}{c}\text { Found } \\
\text { concentration } \\
/ \mu \mathrm{g} \mathrm{g}^{-1}\end{array}$ & $\begin{array}{c}\text { Reference } \\
\text { value } \\
/ \mu \mathrm{g} \mathrm{g}^{-1}\end{array}$ & $\begin{array}{c}\text { Relative } \\
\text { difference, } \\
\%\end{array}$ & $\begin{array}{c}\text { Absolute } \\
\text { difference } \\
/ \mu \mathrm{g} \mathrm{g}^{-1}\end{array}$ \\
\hline \multirow{2}{*}{ IAEA-153 } & $\mathrm{Br}$ & $12.24 \pm 0.48$ & 12.32 & 0.68 & -0.083 \\
\hline & I & $8.11 \pm 0.17$ & 8.15 & 0.55 & -0.045 \\
\hline IAEA-140 & $\mathrm{Br}$ & $562.9 \pm 12.05$ & 567 & 0.72 & -4.10 \\
\hline$/ \mathrm{TM}$ & I & $988.6 \pm 8.8$ & 995 & 0.64 & -6.40 \\
\hline
\end{tabular}

Table 5 Analysis of selected bio-samples

\begin{tabular}{clcc}
\hline \multirow{2}{*}{ No. } & \multirow{2}{*}{ Sample name } & \multicolumn{2}{c}{ Content/ $/ \mathrm{g} \mathrm{g}^{-1}$} \\
\cline { 3 - 4 } & & $\mathrm{Br}$ & $\mathrm{I}$ \\
\hline \multirow{2}{*}{1} & Brassica oleracea capitata & $21.46 \pm 0.72$ & $0.63 \pm 0.037$ \\
2 & Ipomoea aquatica & $20.93 \pm 0.97$ & $3.75 \pm 0.129$ \\
3 & Limnophila aromatica & $38.57 \pm 1.55$ & $1.55 \pm 0.036$ \\
4 & Cabbage (CRM IAEA-359) & $17.66 \pm 0.92$ & $3.53 \pm 0.145$ \\
\hline
\end{tabular}

are given in Table 4. The differences confirm the high accuracy of the method, suggesting that it can be applied for routine analysis of $\mathrm{Br}$ and $\mathrm{I}$ in bio-samples.

\section{Analysis of bio-samples}

The optimized procedure was applied for the determination of $\mathrm{Br}$ and $\mathrm{I}$ in local vegetable samples (young leaves of cabbage (Brassica oleracea capitata), water spinach (Ipomoea aquatica), water coriander (Limnophila aromatica)) and in the CRM IAEA-359, which has a cabbage matrix. The bio-samples were freshly collected and pre-treated as described under Experimental. The sample solutions together with a $10 \mathrm{ng} \mathrm{g}^{-1}$ Te internal standard were measured under the optimum operating condition of ICP-MS (see Apparatus); for Te the mass 125 was selected. The results are given in Table 5 .

The obtained values of $\mathrm{Br}$ and $\mathrm{I}$ in the CRM IAEA-359 agreed by better than $1 \%$ with the certified value of $17.80 \mu \mathrm{g} \mathrm{g}^{-1}$ for $\mathrm{Br}$ and the information value of $3.55 \mu \mathrm{g} \mathrm{g}^{-1}$ for I. The analytical result of all studied samples was thus reliable under identical 
conditions, and the procedure was confirmed to be applicable for the routine analysis of bio-samples for food control.

\section{Conclusions}

This work demonstrates the ability to determine bromine and iodine in biological samples using a simple digestion procedure. Matrix effects and interferences were overcome by using internal standards. The analytical procedure provides accurate results and it is applicable for the routine analysis of different types of bio-samples.

\section{Acknowledgements}

The authors are thankful to Mr. Do Van Thuan (Laboratory Technician) for fruitful cooperation concerning samples treatment, and to Mr. Pham Ngoc Khai (a researcher) for well carrying out some preliminary experiments. The work was partially supported under the framework of the VINATOMCB11/03-01 project.

\section{References}

1. V. R. Preedy, G. N. Burrow, and R. Watson (eds.), "Comprehensive Handbook of Iodine: Nutritional, Biochemical, Pathological and Therapeutic Aspects", 2009, Academic Press, Burlington.

2. World Heath Organization, "The WHO recommended classification of pesticides by hazard and guidelines to classification: 2009", 2010, Wiss. Verlagsges. GmbH, Stuttgart.

3. P. Bendig, L. Maier, and W. Vetter, Food Chem., 2012, 133, 678.

4. S. Pavelka, Physiol. Res., 2004, 53 (Suppl.1), S81.

5. D. Brownstein, "Iodine, Why You Need It and Why You Can't Live Without It", 2008, Medical Alternative Press, W.
Bloomfield.

6. H. J. M. Bowen, Biochem. J., 1959, 73, 381.

7. K. Boutakhrit and F. Bolle, "The determination of iodine in food with the ELAN DRC-e ICP-MS", 2010, Perkin Elmer Application Report.

8. J. S. Edmonds and M. Morita, Pure Appl. Chem., 1998, 70, 1567.

9. F.-M. Lin, H.-L. Wu, H.-S. Kou, and S.-J. Lin, J. Agric Food Chem., 2003, 51, 867.

10. W. Buchberger and U. H. Wolfgang, Microchim. Acta, 1989, 99, 137.

11. A. A. Oliveira, L. C. Trevizan, and J. A. Nobrega, Appl. Spectrosc. Rev., 2010, 45, 447, and references cited therein.

12. M. F. Mesko, P. A. Mello, C. A. Bizzi, V. L. Dressler, G Knapp, and E. M. M. Flores, Anal. Bioanal. Chem., 2010, $398,1125$.

13. R. Zywicki, D. Winter, and M. Dallman, in Abstract of the 123rd AOAC INTERNATIONAL Annual Meeting and Exposition, 2009, Philadelphia, PA, USA.

14. A. L. H. Muller, P. A. Mello, M. F. Mesko, F. A. Duarte, V. L. Dressler, E. I. Muller, and E. M. M. Flores, J. Anal. At. Spectrosc., 2012, 27, 1889.

15. P. K. Dasgupta, Y. Liu, and J. V. Dyke, Environ. Sci. Technol., 2008, 42, 1315.

16. L. H. Pacquette, A. M. Levenson, and J. J. Thomson, J. AOAC Int., 2012, 95, 169.

17. P. Allain, Y. Mauras, C. Douge, L. Jaunault, T. Delaporte and C. Beaugrand, Analyst, 1990, 115, 813.

18. M. Rose, P. Miller, M. Baxter, G. Appleton, H. Crews, and M. Croasdale, J. Environ. Monit., 2001, 3, 361.

19. V. Romaris-Hortas, A. Moreda-Pineiro, and P. BermejoBarrera, Talanta, 2009, 79, 947.

20. K. Tagami, S. Uchida, I. Hirai, H. Tsukada, and H. Takeda, Anal. Chim. Acta, 2006, 570, 88.

21. ISO/IEC 17025, "General Requirements for the Competence of Testing and Calibration Laboratories", 2nd ed., 2005. International Organization for Standardization.

22. C. L. L.Paredes, Thesis, 2009, Univ. of Natural Resources and Life Sciences, Vienna. 